\title{
Analysis of English Language Needs in Elementary School in terms of Geographical Aspects
}

\author{
Rahmat $^{1}$,Dian Firdiani ${ }^{2}$, Ita Sarmita Samad ${ }^{3}$ \\ ${ }^{1}$ (Primary School Teacher Education Department, Universitas Muhammadiyah Enrekang, Indonesia) \\ ${ }^{2}$ (Primary School Teacher Education Department, Universitas Muhammadiyah Enrekang, Indonesia) \\ ${ }^{3}$ (English Department, Universitas Muhammadiyah Enrekang, Indonesia)
}

* Corresponding Author. E-mail: ${ }^{3}$ itaneverendita@gmail.com

Receive: $12 / 10 / 2020$

Accepted: $19 / 10 / 2020$

Published: 28/10/2020

\begin{abstract}
English-Indonesia)
The status of English lessons in the 2013 curriculum is an alternative extracurricular program. This means that schools are given a policy to choose to teach English asextracurricular program or not. Especially for Enrekang District, Enrekang Regency, many elementary schools chose not to program it. Meanwhile, from a geographical perspective, Enrekang Regency is directly adjacent to Tana Toraja Regencywhich is an international tourism area. Thus, human resources around the area should be equipped with English skills. The aims of this research are: 1) to analyze the need for English as an extracurricular program in elementary schools in Enrekang Regency in terms of geographical aspects. 2) to identify the learning approach to teach English that is in accordance with elementary school students need inEnrekang Regency in terms of geographical aspects. This study quantitative and qualitative (Mix-Method). The subjects of this study were SDN 41 Enrekang which was determined through purposive sampling technique. Data collection techniques that had been carried out are through questionnaires, in-depth interviews, and documentation studies. The result confirms that English is really needs to be programmed as an extracurricular activity in elementary schools. In addition, both behaviorism and cognitive learning approach can be applied in teaching English in this context. The methods and techniques that can be applied should be consistent with that learning approach and match with the students' actual English needs in a geographical perspective.
\end{abstract}

Keywords: Needs Analysis, English, Extracurricular, Geographical perspective

\begin{abstract}
Abstrak
Status pelajaran Bahasa Inggris pada kurikulum 2013 adalah sebagai program ekstrakurikuler pilihan. Artinya, sekolah diberi kebijakan untuk memilih mengajarkan Bahasa Inggris sebagai program ekstrakurikuler atau tidak. Khusus untuk di Kecamatan Enrekang, Kabupaten Enrekang, banyak pihak sekolah dasar yang memilih untuk tidak memprogramkannya. Sementara itu ditinjau dari aspek geografis, Kabupaten Enrekang berbatasan langsung dengan Kabupaten Tana Toraja yang merupakan daerah wisata Internasional. Dengan demikian, sumber daya manusia di sekitar wilayah tersebut sudah seharusnya dibekali dengan kemampuan Bahasa Inggris. Tujuan penelitian ini yaitu: 1) Untuk menganalisis kebutuhan terhadap Bahasa Inggris sebagai program ekstrakurikuler sekolah dasar di Kabupaten Enrekang ditinjau dari aspek geografis. 2) Untuk mengetahui pendekatan pembelajaran Bahasa Inggris yang sesuai dengan siswa sekolah dasar di Kabupaten Enrekang ditinjau dari aspek geografis. Penelitian ini menggunakan pendekatan kuantitatif dan kualitatif (Mix-Method). Subjek penelitian ini adalah SDN 41 Enrekang yang
\end{abstract}


ditentukan melaluiteknik purposive sampling. Teknik pengumpulan data yang telah dilakukan adalah melaluikuesioner, wawancara mendalam, dan studi dokumentasi. Hasil analisis data penelitian menunjukan bahwa Bahasa Inggris sangat dibutuhkan untuk diprogramkan sebagai ekstrakurikuler di SD. Selain itu, pendekatan pembelajaran Bahasa baik behaviorism maupun cognitivism dapat digunakan dalam pengajaran Bahasa Inggris dalam konteks ini. Metode dan Teknik pembelajaran yang dapat diterapkan sebaiknya tetap konsisten dengan pendekatan tersebut dan tetap memenuhi kebutuhan actual Bhasa Inggris siswa ditinjau dari aspek geografis.

\section{Pendahuluan}

Mata pelajaran Bahasa Inggris dalam kurikulum 2013 hanya dijadikan sebagai program

ekstrakurikuler pilihan. Dengan demikian, sekolah berhak memilih apakah menjadikan Bahasa Inggris sebagai kegiatan ekstrakurikuler atau tidak. Begitupun dengan siswa, mereka dibolehkanmemilih mengikuti program tersebut atau tidak. Berdasarkan penilaian kinerja kepala sekolah tahunan (2017) yang dilakukan oleh salah satu pengawas di Kecamatan Enrekang diperoleh data bahwa tidak ada satu pun dari 10 sekolah dasar di bawah wilayah binaannya yang memprogramkan ekstrakurikuler Bahasa Inggris.

Dijelaskan bahwa memang ada diantara beberapa sekolah tersebut yang pernah menjalankan

namun hanya bertahan dalam jangka waktu beberapa bulan saja.

Sementara itu, Bahasa Inggris merupakan salah satu keterampilan yang baiknya dipelajari

sejak dini. Piaget dalam Cameron (2001) mengatakan bahwa seorang anak akan mendapatkan

peluang yang besar untuk mendapatkan keterampilan bahasa yang mumpuni ketika dia

mempelajarinya sejak dini. Selain itu, sebagian besar masyarakat khususnya orangtua siswa berpendapat bahwa Bahasa Inggris merupakan salah satu keterampilan yang mesti dikuasai di erayang kompetitif seperti sekarang ini.

Ditinjau dari aspek geografis, Kabupaten Enrekang merupakan daerah yang berbatasan langsung dengan Kabupaten Tana Toraja (Tator) yang merupakan kawasan wisata internasional.Selain itu, pembangunan bandara internasional sedang dioptimalkan di daerah tersebut. Enrekangsering dijadikan sebagai tempat persinggahan oleh para turis domestik bahkan mancanegara yangbertujuan ke Tator.

Beberapa objek wisata terbaru seperti Buttu Macca dan Dante Pine juga tengah mendapatkan animo yang tinggi oleh masyarakat setempat dan dari daerah lain. Tidak menutup kemungkinan, beberapa tahun kedepan, objek wisata ini dapat berkembang sehingga mampu menjadi daya tarik bagi turis-turis asing untuk berkunjung ke sana. Dengan demikian,

masyarakat Kabupaten Enrekang tentunya harus bersiap dengan hal tersebut, salah satunya

dengan memiliki kemampuan berkomunikasi menggunakan Bahasa Internasional yakni Bahasa Ingris.

Untuk itu, disarankan bagi pihak sekolah dasar yang ada di Kabupaten Enrekang untuk

memprogramkan Bahasa Inggris sebagai ekstrakurikuler. Namun sebelum itu, tentu diperlukan suatu usaha untuk menganalisis kebutuhan Bahasa Inggris tersebut sebagai langkah awal untuk memperoleh data yang akurat mengenai bentuk pengajaran yang efektif. Dengan demikian, tim peneliti bermaksud melakukan penelitian dengan judul Analisis Kebutuhan Bahasa Inggris di SDDitinjau dari Aspek Geografis.

Adapun tujuan khusus dari penelitian ini adalah untuk menjawab pertanyaan penelitian 
Jurnal Edumaspul, 4 (2), Year 2002- 207

(Rahmat, Dian Firdiani, Ita Sarmita Samad)

berikut: (1) Bagaimana kebutuhan terhadap Bahasa Inggris sebagai program ekstrakurikuler

sekolah dasar di Kabupaten Enrekang ditinjau dari aspek geografis? (2) Bagaimana pendekatan pembelajaran Bahasa Inggris yang sesuai dengan siswa sekolah dasar di Kabupaten Enrekang ditinjau dari aspek geografis?

Tim peneliti berharap agar hasil dari penelitian ini: (1) dapat memfasilitasi siswa dalam

pemenuhan kebutuhan Bahasa Inggris sejak dini, (2) dapat menjadi acuan yang memudahkan

guru untuk mengajarkan Bahasa Inggris dan memotivasi kepala sekolah memprogramkan BahasaInggris sebagai program ekstrakurikuler di sekolah dasar, (3) mampu berkontribusi dalam duniapendidikan dengan meningkatkan produktivitas pendidikan yang berkualitas dan relevan dengankebutuhan, (4) dapat menjadi sarana untuk meningkatkan professionalisme kerja bagi timpeneliti sebagai tenaga pengajar khususnya dalam hal berbagi ilmu serta mendukungpeningkatan mutu pendidikan di Indonesia dan menjadi referensi yang bernilai bagi penelitiselanjutnya.

\section{Metode}

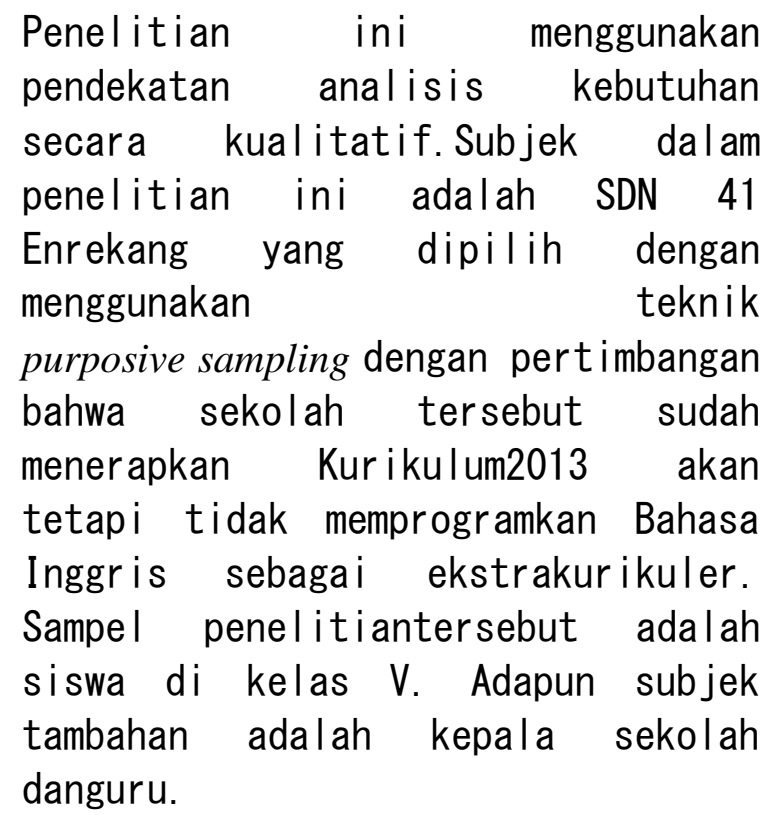

Untuk mengumpulkan data, kami akan menggunakan instrument berupa kuesioner, wawancara mendalam, dan studi dokumentasi.

Kuesionerdisajikan dengan pertanyaan tertutup agar lebih memudahkan subjek penelitian yang merupakan anak-anak dalam menjawab pertanyaan. Kuesioner dibagi menjadi 2 bagian. Pertama mencakup pertanyaan tentang informas $i$ identitas mahasiswa dan bagian kedua mencakup 3 sub-bagian: 1 . Respon siswa terhadap pembelajaran bahasa Inggris, 2. Kebutuhan Bahasa Inggris siswa (kecenderungan keterampilan Bahasa Inggris, Kesulitan dalam belajar bahasa Inggris), 3. Preferensi gaya belajar.

Wawancara dilakukan dengan model wawancara mendalam dengan menggunakan

wawancara terstruktur. Wawancara dilakukan untuk memperoleh data dar i guru maupun kepala sekolah tentang kebutuhan pembelajaran bahasa Inggr is di SD.

Studi dokumentasi dilakukan untuk mendukung data yang diperoleh dari hasil kuesioner. Dokumen yang dikaji berupa RPP, Silabus, buku ajar yang diterapkan di sekolah responden dan buku lain terkait pembelajaran Bahasa Inggris di SD dan Bahasa Inggris untuk pariwisata.

Selanjutnya data yang telah dikumpulkan dianalisis berdasarkan langkah-langkah analisis data kualitatif yang dikembangkan oleh Gay danAirasian (2006) yang terdiri atas 5 tahapan: Mengolah, membaca, 
mendeskr ips ikan, mengk las if ikas ikan, dan menginterpretasi.

\section{Hasil dan Pembahasan}

Data yang diperoleh dari penelitian menggunakan analisis kebutuhan ini perlu untuk diinterpretasikan pada fokus penelitian. Terdapat 2 pertanyaan penelitian yaitu yang pertama fokus pada bagaimana kebutuhan Bahasa Inggris sebagai program ekstrakurikuler ditinjau dari aspek geografis dan yang ke-dua fokus pada jenis pendekatan pembelajaran Bahasa Inggris yang sesuai dengan kebutuhan Bahasa Inggris di SD.

Pertama-tama kita mulai dengan menganalisis data terkait sikap siswa terhadap pembelajaran Bahasa Inggris. Berdasarkan data yang dikumpulkan melalui kuesioner oleh 18 siswa maka diketahui bahwa jawaban mereka menyiratkan baik motivasi intrinsik maupun ekstrinsik. Sebuah kabar baik bahwa motivasi intrinsik mereka terhadap pembelajaran Bahasa Inggris sangat dominan. Diketahui dari hasil kuesioner bahwa dari 18 responden, keseluruhan menjawab iya untuk pernyataan "karena saya suka belajar Bahasa Inggris". Contoh lain: karena Bahasa Inggris adalah bahasa internasional/ bahasa yang penting (17/18), agar bisa paham dengan teks berbahasa Inggris (17/18), agar bisa lulus ujian Bahasa Inggris (17/18). Hal ini sangat baik karena dapat memberikan manfaat pembelajaran yang jauh lebih besar baik dalam jangka pendek maupun jangka panjang (Tzouzou, 2014). Ketika siswa pada dasarnya sudah senang belajar Bahasa Inggris, maka akan memudahkan proses pembelajaran nantinya sehingga dapat mendukung hasil belajar yang efektif. Hasil wawancara yang dilakukan baik dengan guru maupun kepala sekolah menyiratkan bahwa mereka paham betul pentingnya Bahasa Inggris diajarkan sejak dini bagi siswa mereka di sekolah dasar. Mereka beralasan bahwa Bahasa Inggris sebagai bahasa internasional akan sangat menunjang prestasi ataupun karir siswa mereka di masa depan. Selain itu, letak geografis Kabupaten Enrekang yang memiliki objek wisata memungkinkan anak-anak dapat berlatih berinteraksi langsung dengan para turis asing yang berkunjung. Fakta ini mengkonfirmasi bahwa Bahasa Inggris memang perlu diprogramkan sebagai kegiatan ekstrakurikuler di SD.

Selanjutnya, peneliti menganalisis hasil data kuesioner terkait kebutuhan Bahasa Inggris siswa (kecenderungan keterampilan Bahasa Inggris yang disenangi dan kesulitannya dalam belajar Bahasa Inggris). Dari data, diperoleh bahwa siswa lebih cenderung menyukai keterampilan menulis (17/18), membaca (16/18), mendengarkan (9/18), berbicara (7/18). Kebanyakan siswa beranggapan bahwa mereka masih kurang atau sulit dalam hal mendengarkan dan berbicara. Meskipun pada dasarnya respon siswa terhadap kesulitan mereka belajar bahasa Inggris menunjukan bahwa rerata mereka masih perlu belajar lebih untuk semua jenis keterampilan berbahasa tersebut. Dengan demikian, yang perlu diperhatikan nantinya pada saat penyusunan silabus adalah meneliti secara seksama dan cermat hal-hal yang dianggap mampu membuat penyesuaian atau perbaikan yang diperlukan untuk mengatasi kelemahan atau kegagalan siswa terutama dalam keterampilan berbicara dan mendengarkan dan akhirnya membantu siswa mengatasi kesulitan mereka seefektif mungkin.

Terkait dengan kecenderungan gaya belajar siswa, data yang diperoleh bahwa kecenderungan siswa dalam hal ini anakanak pada umumnya lebih suka belajar dengan permainan, aktivitas internet dan teknologi komputer. Oleh karena itu, hal ini menyiratkan agar kurikulum, buku pelajaran, materi dan metode guru yang akan digunakan haruslah memenuhi preferensi belajar anak-anak agar dapat mendukung keefektifan pembelajaran. Dalam hal ini, guru sebaiknya memperkaya ilmu/ keterampilan mereka dalam 
mengelola kelas terutama dari strategi mengajar yang digunakan agar bisa sesuai dengan preferensi gaya belajar siswa.

Berdasarkan data kuesioner juga ditemukan fakta bahwa strategi belajar siswa baik dalam hal belajar kosakata ataupun tata bahasa, rerata siswa mengiyakan semua poin pernyataan kuesioner yang ada. Strategi belajar kosakata baru: dengan mendengarkan kosakata baru (18/18), dengan melihat kosakata baru (15/18), dengan mengulang kosakata (16/18), dengan menerjemahkan kosakata (16/18). Strategi belajar tatabahasa: dengan mempelajari rumus tata bahasa (16/18), dengan latihan tertulis di sekolah (18/18), dengan latihan tertulis di rumah (14/18), dengan latihan praktek secara lisan di sekolah (16/18). Untuk itu, dalam menyusun silabus ataupun RPP, guru sebaiknya mengintegrasikan strategi gaya belajar siswa tersebut.

Fakta yang lain terkait kecenderungan belajar siswa adalah terkait dengan materi/tema yang mereka senangi dalam belajar. Berikut 10 tema yang mendapati respon paling tinggi: Kebudayaan/ Kebiasaan, Lingkungan/ Alam, Kesehatan, Internet, Makanan/ Masakan, Keluarga/ Teman/ Orang/ Relasi, Waktu Luang/ Hobby, Sejarah/ kisah/ cerita, Seni/ Melukis, Bumi. Tema-tema ini dapat diaplikasikan dalam pembelajaran dengan menggunakan materi autentik sesuai dengan lingkungan sekitar siswa.

\section{Simpulan}

Data hasil Analisis Kebutuhan di atas mengungkapkan kebutuhan Bahasa Inggris siswa SD ditinjau dari aspek geografisnya yang kemudian direfleksikan untuk menyusun kurikulum/ silabus. Hal ini bertujuan agar apa yang dirancang oleh guru memang sesuai dengan kebutuhan aktual siswa.

Sebagai contoh, penggunaan pendekatan behaviorism ataupun cognitivism, keduaduanya bisa diterapkan dalam pembelajaran
Bahasa Inggris dalam konteks ini. Berdasarkan teori pembelajaran bahasa, behaviorism bermakna sebagai sebuah bentuk kebiasaaan sedangkan cognitivism berpandangan bahwa pembelajaran lebih cenderung kepada proses berfikir daripada bentuk kebiasaan (Alnaqeeb, 2012). Temuan dari analisis kebutuhan yang telah dilakukan mengungkapkan bahwa kecenderungan gaya belajar siswa memberikan respon yang dominan pada pernyataan gaya belajar yang berorientasi pada behaviorism (contoh: dengan mengulang kosakata, dengan latihan praktek) maupun yang berorientasi pada cognitivism (contoh: dengan mempelajari tata bahasa, dengan menerjemahkan kosakata).

Selanjutnya, menentukan metode ataupun teknik yang digunakan dalam proses pembelajaran. Anthony (2014) menjelaskan bahwa dalam rangka mencapai efektifitas pengajaran Bahasa, guru sebaiknya menggunakan teknik yang sesuai dengan metode yang sekaligus konsisten terhadap pendekatan pembelajaran. Oleh karena itu, berikut beberapa teknik yang bisa digunakan untuk disesuaikan dengan hasil temuan analisis kebutuhan pada konteks ini dan tetap konsisten terhadap pendekatan pembelajaran. Pendekatan behaviorism dapat menggunakan teknik translation of literary passage, dialog, dan memorization dan pendekatan cognitivism dapat menerapkan teknik berupa sound color chart, paragraph writing, small group task, fill in the blank exercise, dan reflective listening (Samad, 2016).

Terkait dengan topik/ tema pembelajaran, guru dapat menggunakan materi autentik. Brinton (1991) menyatakan bahwa materi autentik dapat menguatkan hubungan antara kelas bahasa dan dunia luar secara langsung. Dalam konteks ini, guru dapat memanfaatkan tema-tema yang sesuai dengan ciri khas lingkungan di sekitar siswa. Sebagai contoh dalam tema kebudayaan/ kebiasaan, guru dapat 
menggunakan cerita rakyat daerah Enrekang, sejarah, adat istiadat dan sebagainya. Contoh lain, tema tentang masakan/ makanan, guru dapat menggunakan makanan khas daerah Enrekang seperti dangke. Bentuk fisik berupa teks dan makanan dalam contoh tersebut sangat mudah didapatkan di lingkungan siswa sehingga memudahkan mereka untuk membawa materi tersebut ke dalam kelas Bahasa. Hal ini dapat mengefektifkan proses pembelajaran Bahasa.

\section{Daftar Pustaka}

1. Alnaqeeb, A. M. A. (2012). A study of Yemeni English teachers' classroom practices and approaches with special reference to secondary schools in Laboos (Doctoral dissertation, University of Pune, India). Retrieved from

https://www.academia.edu/2770511/a_s tudy_of_yemeni_english_teachers_class room_practices_and_approaches_with_ special_reference_to_secondary_school s_in_laboos

2. Anthony, E. (2014). Approach, method, and technique. Oxford university press journal, 17(2), 63-67, doi:10.1093/elt/xvii.2.63

3. Brown, J. D. (1995). The elements of language curriculum. Boston, U.S.A: Heinle \& Heinle Publishers.

4. Brinton, D. M. (1991). The use of media in language teaching. In $\mathrm{M}$. Celce-Murcia

(Ed.),

Teaching English as a Second or Foreign Language (pp. 454-472). Boston: Heinle and Heinle Publishers

5. Dja' far, V. H. (2017). Anal is is kebutuhan pada pengajaran bahasa inggris di PG-PAUD. Jurnal PG-PAUD Trunojoyo, 4 (2),
92-102.

Doi :

10. $21107 /$ jpgpaud. v4 i 2.3572

6. Gay, L. R., Mills, G. E., \& Airasian, P. (2006). Educational research: Competencies for analysis and appications (8th ed.). Upper Saddle River, New Jersey: Pearson Education, Inc

7. Grave, K. (2000). Designing language courses: A guide for teachers. Boston, U.S.A: Heinle $\&$ Heinle Publishers.

8. KomunitasAtlas. (2012, Januar $\mathrm{i}$ 07). Kabupaten Enrekan (Web log post). Retrieved from https://komunitasat las. blogspot. com/2012/01/kabup aten-enrekang. html.

9. Kusumoto, Y. (2008). Needs analysis: Developing a teacher training program for elementary school homeroom teachers in Japan. Second Language Studies, 26 (2), 1-44.

10. Nation, I. S. P. \& Macalister, J. (2010). Language curriculum design. Madison Ave, NY: Rout ledge.

11. Nunan, D. \& Linse, C. T. (2005). Practical English language teaching: Young learners. Avenue of the Americas, NY: McGraw-Hi I I EST/ELT.

12. Samad, I. S. (2016). A study on English teachers' teaching approaches, methods, and techniques at a state senior high school in Enrekang, Indonesia. Jurnal Bahasa Lingua Scientia, $8(2), 129-146 . \quad$ Do i : 10. $21274 /$ Is. 2016. 8. 2. 129-146.

13. Sari, R. K. (2019). Analisis kebutuhan pembelajaran bahasa Inggris pada mahasiswa kelas karyawan. Susunan Artikel 
Jurnal Edumaspul, 4 (2), Year 2002- 211

(Rahmat, Dian Firdiani, Ita Sarmita Samad)

Pendidikan, $4(1), \quad 38-45 . \quad$ Do i : 10. 30998/sap. v4i1. 3612

14. Septiana, L. (2019). Analysis of English for business administration students. Jurnal Ilmiah

Batanghari Jambi, $19(1)$, 23-26. Doi: $10.33087 /$ jiubj. v19i1. 563.

15. Supriyanti, N. (2012). Why do our children need to learn English at elementary schools? A critical review on the provision of English to the Indonesia elementary schools. In $M$. Syafe'I, H. Madjdi, \& Mutohhar (Eds.), Teaching English for Young Learners in Indonesia(TEYLIN):from Policy to Classroom: The 2nd National Conference on Teaching English for Young Learners, Muria Kudus University, 10-11 July 2012 (pp. 145152). Jakarta, Percetakan Nasional RI: Katalog dalam Terbitan (KDT).

16. Syaiful, F. F., \& Elihami, E. (2020). PENERAPAN ANALISIS SWOT TERHADAP STRATEGI PEMASARAN USAHA MINUMAN
KAMSIA BOBA MILIK ABDULLAH DI TENGAH PANDEMI COVID-19 DI KABUPATEN BANGKALAN. JURNAL EDUKASI NONFORMAL, 1(2), 343-359.

17. Tzotzou, M. D. (2014). Designing and administering a needs analysis survey to primary school learners about EFL learning: A case study. Preschool and Primary Education, 2(1), 59-82. doi: dx.doi.org/10.12681/ppej.62

18. Tasrim, T., \& Elihami, E. (2020). MOTIVASI KERJA PENDIDIK DALAM MENINGKATKAN MANAJEMEN LEMBAGA PENDIDIKAN DASAR. Mahaguru: Jurnal Pendidikan Guru Sekolah Dasar, 1(1), 48-53.

19. Wulansari, D. \& Afifulloh, M. (2018). Pemetaan kebutuhan bahasa Inggris pada masyarakat daerah potensi wisata Kabupaten Bangka Provinsi Kepulauan Bangka Belitung. Jurnal Sains Sosial dan Humaniora, 2(1), 133-144. Doi: 10.30595/jssh.v2i1.2332 